\title{
A EDUCOMUNICAÇÃO COMO CAMPO DO CONHECIMENTO PARA O ENSINO E APRENDIZAGEM NO SÉCULO XXI
}

\author{
EDUCOMMUNICATION AS A KNOWLEDGE AREA FOR THE \\ TEACHING AND LEARNING OF TWENTY-FIRST CENTURY
}

\section{Walter Chalegre dos Santos ${ }^{1}$, Angélica Moreira Pereira ${ }^{2}$ e Taís Steffenello Ghisleni ${ }^{3}$}

\section{RESUMO}

A Educomunicação é uma área de conhecimento relativamente recente, a qual se fundamenta, sobretudo, na interface entre os campos da Comunicação e da Educação. No Brasil ainda estamos praticando educação $2.0 \mathrm{e}$ a tecnologia 4.0. Todos os alunos/as da Educação Básica são nativos digitais, bem como parte dos alunos/as do Ensino Superior, nascidos no século XXI. No entanto, o corpo docente em sua boa parte é nascido no século XX e com parte de sua formação também proveniente do século XX. Assim, esse estudo tem como objetivo geral analisar a Educomunicação como um novo campo do conhecimento para melhorar a relação da docência com os discentes nos ambientes educacionais inovando e modernizando o ensino e aprendizagem. Para tanto, foi necessário explicar o campo da Educomunicação e apresentar sua abordagem histórica inicial para posteriormente refletir sobre a sua inserção no século XXI.

Palavras-chave: Ensino; Aprendizagem; Tecnologia.

\section{ABSTRACT}

Educommunication is a relatively recent area of knowledge, which is based, above all, on the interface between the fields of Communication and Education. In Brazil, we are still practicing education 2.0 and technology 4.0. All Basic Education students are digital natives, as well as part of 21st century higher education students. However, mostly of the faculty professors are born in the twentieth century and with part of its formation also coming from the twentieth century. Thus, this study aims to analyze Educommunication as a new field of knowledge to improve the relationship of teaching with students in educational environments by innovating and modernizing teaching and learning. Therefore, it was necessary to explain the field of Educommunication and present its initial historical approach to later reflect on its insertion in the 21 st century.

Keywords: Teaching; Learning; Technology.

\footnotetext{
${ }^{1}$ Aluno do Mestrado em Ensino de Humanidades e Linguagens da Universidade Franciscana - UFN. E-mail: walter.santos@, centenario.metodista.br

${ }^{2}$ Mestre. Professora do curso de Publicidade e Propaganda - UFN. Coordenadora dos cursos de Especialização em Ciências Sociais - UFN. E-mail: ppmoreira.pereira@gmail.com

${ }^{3}$ Doutora. Professora do Curso de Publicidade e Propaganda e do Mestrado em Humanidades e Linguagens da Universidade Franciscana - UFN. E-mail: taisghisleni@yahoo.com.br
} 


\section{INTRODUÇÃO}

A Educomunicação é uma área de conhecimento relativamente recente, a qual se fundamenta, sobretudo, na interface entre os campos da Comunicação e da Educação. De acordo com Ismar de Oliveira Soares $(2011)^{4}$, as pesquisas na área remontam ao início do século XX, quando nos Estados Unidos e em alguns países da Europa, os trabalhos com Media Literacy e Media Education ganharam força. Na América Latina, pesquisas e experiências práticas em Comunicação/Educação também começaram a conquistar espaço, a partir dos anos 1980, através de estudiosos como Paulo Freire, Jesús Martín-Barbero e Mário Kaplún. O educador brasileiro Paulo Freire é um dos pioneiros na inter-relação Comunicação/Educação, considerando a comunicação como um componente indispensável ao processo educativo (SOARES, 2011).

Segundo Ismar de Oliveira Soares (2011, p.17) uma comunicação essencialmente dialógica e participativa, no espaço do ecossistema comunicativo escolar, mediada pela gestão compartilhada (professor/aluno/comunidade escolar) dos recursos e processos da informação, contribui essencialmente para a prática educativa, cuja especificidade e o aumento imediato do grau de motivação por parte dos estudantes, e para o adequado relacionamento no convívio professor/aluno, maximizando as possibilidades de aprendizagem, de tomada de consciência e de mobilização para a ação. A essa precondição e a esse esforço multidisciplinar denominamos educomunicação.

No Brasil ainda estamos praticando educação 2.0 e a tecnologia 4.0. Todos os alunos/as da Educação Básica são nativos digitais, bem como parte dos alunos/as do Ensino Superior, nascidos no século XXI. No entanto, o corpo docente em sua boa parte é nascido no século XX e com parte de sua formação também proveniente do século XX.

A partir dessa contextualização inicial, o problema de pesquisa que busca responder neste estudo é: A Educomunicação como um novo campo do conhecimento melhora a relação da docência com a discência nos ambientes educacionais inovando e modernizando o ensino e aprendizagem?

Assim, esse estudo tem como objetivo geral analisar a Educomunicação como um novo campo do conhecimento para melhorar a relação da docência com os discentes nos ambientes educacionais inovando e modernizando o ensino e aprendizagem. Para tanto, foi necessário explicar o campo da educomunicação e apresentar sua abordagem histórica inicial para posteriormente refletir sobre a sua inserção no século XXI.

\footnotetext{
${ }^{4}$ Jornalista e doutor em comunicação pela ECA/USP, com pós-doutorado na Marquette University, Estados Unidos, coordenador e fundador do Núcleo de Comunicação e Educação da Universidade de São Paulo (NCE/USP), precursor da educomunicação no Brasil, principal responsável pela sistematização do pensamento educomunicacional
} 


\section{CONCEITOS DE EDUCOMUNICAÇÃO}

O conceito de educomunicação é definido por Soares (2011, p. 44) como "um conjunto de ações inerentes ao planejamento, implementação e avaliação de processos, programas e produtos destinados a criar e a fortalecer ecossistemas comunicativos".

Quando se fala sobre educomunicação a primeira impressão é que tem haver com a utilização de tecnologia no ambiente educacional. Mas para o NCE-ECA USP, a Educomunicação define-se como um conjunto das ações destinadas a:

1. Integrar às práticas educativas o estudo sistemático dos sistemas de comunicação, cumprindo o que solicita os PCNs no que diz respeito a observar como os meios de comunicação agem na sociedade e buscar formas de colaborar com nossos alunos para conviverem com eles de forma positiva, sem se deixarem manipular;

2. Criar e fortalecer ecossistemas comunicativos em espaços educativos. O que significa criar e rever as relações de comunicação na escola, entre direção, professores e alunos, bem como da escola com a comunidade, criando sempre ambientes abertos e democráticos.

3. Melhorar o coeficiente expressivo e comunicativo das ações educativas.

A Educomunicação necessita que sejam observados alguns procedimentos sem o quais fica irreconhecível, entre estes:

a) É necessário prever e planejar conjuntos de ações, no contexto do plano pedagógico das escolas, e não ações isoladas (uma ação isolada não modifica as relações de comunicação num ambiente marcado por práticas autoritárias de comunicação);

b) Todo planejamento deve ser participativo envolvendo todas as pessoas envolvidas como agentes ou beneficiárias das ações (por isso, convidamos os professores, alunos e membros das comunidades a desenvolverem planejamentos conjuntos);

c) As relações de comunicação devem ser sempre francas e abertas (a educomunicação busca rever os conceitos tradicionais de comunicação, como se existisse apenas para persuadir ou fazer a boa imagem dos que detêm poder e fama. Aqui, a comunicação é feita para socializar e criar consensos);

d) O objetivo principal é o crescimento da auto-estima e da capacidade de expressão das pessoas, como indivíduos e como grupo. (SOARES, 2004, p.44).

A Educomunicação vai se preocupar com as tecnologias, não por serem tecnologias, mas por serem parte das mediações que a cultura contemporânea apresenta para garantir formas de expressão (SOARES, 2014).

Um dos pioneiros na inter-relação comunicação/educação no cenário latino americano, Paulo Freire focaliza os processos comunicacionais que se inserem no agir pedagógico libertador. Ele afirma que o homem é um ser de relação e não só de contatos como o animal, não está apenas no mundo, mas com o mundo. Além da ideia de emancipação, surge a concepção do coletivo, do sentido de grupo, que deve prevalecer sobre o indivíduo, no compartilhamento e na busca da ação libertadora.

Nessa mesma direção aponta o educador chileno Mário Kaplún, que define a inter-relação como "comunicação educativa", destacando sua natureza: ela existe para dar à educação métodos e procedimentos para formar a competência comunicativa do educando. Não se trata de educar usando 
o instrumento da comunicação, mas que ela se converta no eixo vertebrador dos processos educativos: educar pela comunicação e não para a comunicação.

Dentro de todo esse contexto, repensar o conceito de formação é fundamental. Não basta incluir a tecnologia na prática pedagógica, como adendo ou atrativo do conhecimento. É preciso preparar os educadores para exercerem um papel de mediadores nesse novo cenário tecno-informativo.

Segundo Citelli (2011), formação é um ato de apreensão e completude do sujeito na relação dele com o mundo, é um processo de retroalimentação que tem uma tensão permanente entre a experiência e a prática. É nesse sentido que o processo de formação deve estar aberto para trabalhar com outros elementos comunicativos, entendendo que a comunicação é parte intrínseca desse conhecimento.

\section{ASPECTOS HiSTÓRICOS DA APROXIMAÇÃO ENTRE A COMUNICAÇÃo E A EDUCAÇÃO}

Nos anos de 1970 e seguintes, os especialistas tinham seus olhos voltados para países como a Inglaterra, a Austrália e o Canadá, identificando-os como referências na área da Educação Midiática, pela originalidade e abrangência de seus programas, assim como pelo apoio que recebiam de seus respectivos governos. Nos Estados Unidos, o reconhecimento e a valorização do assunto oscilaram na dependência do envolvimento do governo: em períodos republicanos, pouco apoio; já em tempos democratas, relativa expansão, especialmente nas escolas públicas. No final do primeiro mandato de Clinton, por exemplo, a Media Literacy, até então presente nos programas educativos de apenas 12 dos estados, alcançou definitivamente os parâmetros curriculares (Academic Standards) de todas as unidades federadas. ${ }^{5}$

Na Europa, no início de 2007, era o governo francês que informava haver adotado a Éducation aux Médias como conteúdo curricular obrigatório em todas as escolas do país, isso depois de um longo esforço da Clemi, instituição mantida pelo Ministério da Educação, cujo trabalho foi o de estimular e formar professores para o desenvolvimento de atividades no campo. Na América Latina, o tema não chegou a ganhar status de política pública, permanecendo restrito à iniciativa de indivíduos, grupos isolados ou instituições formadas por religiosos, educadores, acadêmicos ou ativistas políticos do Movimento Popular, sem nunca ter provocado um consenso sobre metas, objetivos ou metodologias.

No Brasil, a partir da década de 1990, para a construção de uma prática educativa inovadora são abordadas as iniciativas da Faculdade de Educação da UNICAMP e da Universidade de São Paulo (USP), no sentido de promover a aproximação entre a comunicação e a educação, com o objetivo de aportar novas contribuições à formação profissional de educadores e comunicólogos. A inter-relação comunicação e educação constituem um campo de intervenção social, denominado de educomunicação,

\footnotetext{
${ }^{5}$ Uma visão de como a intelectualidade norte-americana valoriza a educação midiática pode ser obtida com a leitura do paper Confronting the Challenges of Participatory Culture: Media Education for the 21st Century, de henry Jenkins (coord.), diretor do comparative media studies program, do massachu setts institute of technology. Disponível em: https://bit.ly/3kWg7N2. Acesso em: 11 jul. 2014.
} 
que se caracteriza por uma ação política, voltada para o aporte de uma consciência ética e uma pragmática direcionada para as transformações da sociedade. Essa ação se firma na formação de cidadãos críticos, participativos e inseridos no meio social, e na concretização de utopias sociais de uma educação de qualidade e de uma comunicação participativa e democrática (SCHAUN, 2002, p. 82).

O avanço dos meios de comunicação, impulsionado pelo desenvolvimento tecnológico, produziu mudanças de hábitos e comportamentos, exigindo uma postura mais reflexiva e uma educação com os meios que esteja pautada na inclusão, na ética e na cidadania, amparada por uma pedagogia da comunicação, a qual apresenta uma abordagem pedagógica dos meios de comunicação nos ambientes de ensino e aprendizagem.

A partir desta concepção, entende-se que é necessária uma nova proposta pedagógica que aproveite a potencialidade dos recursos tecnológicos, aliada a uma postura ativa e capaz de estimular as interações sociais, a colaboração, a reflexão e a construção de novos conhecimentos que levem à autonomia dos sujeitos. As transformações no ambiente de aprendizagem requerem também uma mudança no papel do educador.

Novas formas de acessar a informação, de pensar, de raciocinar e novas dinâmicas no aprender evidenciam a transformação do pensamento linear para o pensamento hipertextual no processo de construção do conhecimento. Espaços abertos, conhecimentos emergentes, articulação de saberes, processos auto-organizativos requerem a transformação da prática pedagógica e exige dos educadores uma postura que reconheça o aprendiz na sua multidimensionalidade e favoreça a aprendizagem individual e coletiva (DELCIN, 2005, p. 56).

De 1998 até este início de segunda década do século XXI (2014), a observação de Davadoss segundo a qual o tema da relação Comunicação/ Educação, na perspectiva educomunicativa, havia ultrapassado a questão da mídia para adentrar a área da cultura não apenas se confirmou, como abriu portas nas políticas públicas, facilitando o ingresso da Educação Midiática onde até há poucos anos o sistema educativo resistia em discutir o assunto.

Tornou-se clássico o exemplo do Educom.rádio, da Secretaria de Educação do Município de São Paulo: um projeto voltado a combater a violência nas escolas e incentivar uma prática de convivência cidadã, numa rede complexa de escolas, espalhadas pelo território de uma cidade da magnitude de São Paulo, mediante o planejamento e uso colaborativo dos recursos da informação (inicialmente o rádio, depois o vídeo e a linguagem digital), articulando em igualdade de condições e de forma plenamente democrática professores, estudantes e membros da comunidade educativa, acabou criando raízes suficientes para manter a proposta no decorrer de sucessivas administrações públicas, comandadas por partidos adversários, todos reconhecendo as conquistas, que permitiram que, em 2010, a prática da produção midiática chegasse às crianças da educação infantil, com a criação de suas "emissoras de rádio" ou "miniestações de vídeo/TV", totalmente conduzidas por crianças de 6 a 8 anos de idade. 
Outro exemplo clássico foi a adoção do conceito e da prática educomunicativa por parte do Ministério do Meio Ambiente, tendo como objetivo promover a educação midiática de gestores encarregados das áreas de preservação socioambiental. O empoderamento midiático passou a permitir que um número crescente de jovens se interessasse por fazer uso da palavra e dos veículos de informação para defender os "direitos da terra", ameaçados por um mercado hostil aos interesses da preservação da vida no planeta.

Os dois exemplos somados aos milhares que podem ser colhidos em todo o território nacional demonstram que a perspectiva educomunicativa de voltar-se prioritariamente aos problemas de cultura e, secundariamente, à questão dos meios de informação, havia produzido um efeito jamais testemunhado de interesse pela Educação Midiática no país. Garantiu, dessa forma, a abertura de portas anteriormente fechadas para o tema, tanto no âmbito do sistema educativo formal quanto no espaço da educação não formal.

Para o exercício de seu escopo, o conceito da Educomunicação pressupõe, contudo, a autonomia epistemológica de sua ação, uma vez que busca sua sustentação não exatamente nos parâmetros da Educação (em suas filosofias ou didáticas) ou, mesmo, da Comunicação (em suas teorias e práticas), mas na interface entre ambas (o mundo que se revela no encontro dos dois campos tradicionais).

No caso, a Educomunicação dialoga com a Educação, tanto quanto com a Comunicação, ressaltando, por meio de projetos colaborativamente planejados, a importância de se rever os padrões teóricos e práticos pelas quais a comunicação se dá. Busca, desta forma, transformações sociais que priorizem, desde o processo de alfabetização, o exercício da expressão, tornando tal prática solidária fator de aprendizagem que amplie o número dos sujeitos sociais e políticos preocupados com o reconhecimento prático, no cotidiano da vida social, do direito universal à expressão e à comunicação (SOARES, 2014).

Ao ressaltar a novidade trazida pela expansão do conceito da Educomunicação, vinculado ao Protocolo Mediático, não pretendemos minimizar nenhum outro esforço que esteja sendo promovido por projetos sob outras denominações e com outros fundamentos. O progresso de uns favorece o sucesso dos demais.

\section{REFLEXÕES SOBRE OS DESAFIOS DA EDUCOMUNICAÇÃO}

As tradicionais agências de socialização - escola e família - vêm se confrontando, nos últimos tempos, com os meios de comunicação, que se constituem em outra agência de socialização. O processo comunicação/educação merece o lugar de segmento prioritário das teorizações e das pesquisas no campo da comunicação, pois permite que se leve em conta, sobretudo, o papel da mídia na configuração da cultura. A comunicação também passa a ser uma agência de socialização onde a escola já não é mais o único "lugar do saber". 
Para que atuemos com êxito no complexo campo comunicação/educação, vários desafios se evidenciam (BACCEGA 2009), tais como reconhecer os meios de comunicação como outro lugar do saber. É preciso entender que o campo comunicação/educação não se reduz a fragmentos, por exemplo, a eterna discussão sobre a adequação da utilização das tecnologias no âmbito escolar. Faz-se necessário avançar a elaboração do campo, mostrando comunicação/educação como o lugar onde os sentidos se formam e se desviam, emergem e submergem: a sociedade, com seus comportamentos culturais, levando-se em conta, principalmente, a pluralidade de sujeitos - a diversidade de identidade que habita cada um de nós.

Conhecer a diversidade de que a multi, inter e transdisciplinaridade estão plenas e reconhecer que o campo só pode ser pensado a partir delas, pois é preciso verificar criticamente que a realidade em que estamos imersos, e que contribuímos para produzir, modificar e reproduzir, é sempre uma realidade mediada e mediatizada.

Outro desafio necessário é compreender por que a realidade contemporânea exige que o conceito de campo cultural seja mais inclusivo, ou seja, que nele esteja um conjunto de relações sociais que incluem atores, instituições e empresas, públicas ou privadas que se voltam para a produção e circulação de bens simbólicos, bem como conhecer e vivenciar os desafios das novas concepções do tempo e espaço.

É necessário ir do mundo editado à construção do mundo. Compreender esse processo é mais um desafio do campo comunicação/educação. Para estudar o campo comunicação/educação, constituído no bojo do campo da comunicação, é preciso, como vimos, estabelecer um diálogo mais amplo, com mais saberes.

A partir disso, consideramos que compete à comunicação/educação levar os sujeitos a construir novos modos de atuação na mídia e no mundo. Eis o desafio básico da reflexão sobre o campo comunicação/educação: o mundo é editado e assim ele chega a todos nós; sua edição obedece a interesses de diferentes tipos, sobretudo econômicos.

\section{EDUCOMUNICAÇÃO E SUAS ÁREAS DE INTERVENÇÃO}

Para Sibilia (2012) aqueles professores que não nasceram nesse novo ambiente envolto às tecnologias, mas foram atravessados por ela e vivenciam suas consequências na 'própria pele', se angustiam com esse novo modo de ser e estar no mundo contemporâneo, pois são mais compatíveis com o modelo tradicional de ensino-aprendizagem, revelando sua "flagrante incompatibilidade com tais ferramentas enquanto se ensamblam com outros artefatos” (SIBILIA, 2012, p. 198).

Em relação aos professores, mesmo que façam uso de seus equipamentos no preparo das aulas, em pesquisas e atividades de formação continuada, ao levarem seus 'notebooks' para o ambiente escolar, esses aparelhos, muitas vezes, não fazem parte do contexto da aula, servindo apenas como suporte para o professor nas atividades docentes. Os professores pouco inovam em propostas metodológicas colaborativas com recursos digitais, apesar de já serem usuários de Internet em suas 
próprias residências. Com isso, em espaços escolares que permitem a utilização dos aparelhos móveis (smartphones e tablets) e também o uso permanente pelos alunos em casa, eles têm se tornado o grande concorrente do professor que perde seu lugar para os sites e aplicativos de pesquisa virtuais. Para Voltolini (2014) esse fenômeno vem despertando algo inédito nos professores: o fantasma da miniaturização do professor, uma vez que ele se depara com um objeto em que os jovens sabem mais do que ele.

Assim, sabemos que os avanços das ferramentas tecnológicas vêm afetando a maneira como os professores pensam e realizam as suas ações pedagógicas. Juntamente com isso questões que vão desde a intensificação burocrática do trabalho docente - capturado por sistemas de informatização - até a quantificação do saber docente, refletida na produção de trabalhos acadêmicos e atividades extracurriculares, também vêm modificando sua prática. Torna-se, pois, importante refletir sobre o uso em sala de aula das diferentes mídias, no que diz respeito às ferramentas de trabalho do professor e o lugar que elas ocupam no seu fazer pedagógico, para compreender, de que forma o mundo virtual vem afetando o fazer docente e a relação dos professores com os alunos.

A educomunicação possui, em sua essência, pressupostos que visam superar possíveis limites conceituais entre as áreas da educação e da comunicação, configurando-se como a interface entre estes campos. A educação, enquanto ação comunicativa, é um fenômeno que permeia todas as maneiras de formação de um ser humano e, assim, sob a mesma ótica, toda ação de comunicação tem, potencialmente, uma ação educativa. Nesse sentido, a construção de uma comunicação dialógica e participativa no ambiente educacional, pautada em uma eficaz gestão compartilhada por órgãos governamentais, administração escolar, docentes, alunos e a comunidade abre oportunas perspectivas de melhoria motivacional e de fortalecimento dos laços entre alunos e professores ao longo do processo de ensino e de aprendizagem.

\section{CONSIDERAÇÕES FINAIS}

A crise de paradigma na educação gerado a partir do surgimento das novas tecnologias e de uma nova demanda social por uma formação mais autônoma, crítica e mais condizente com o atual momento de evolução da sociedade nos leva a pensar que o problema não está na no uso das tecnologias na educação, mas sim, na forma, em como se pode utilizá-las para o desenvolvimento da autonomia e da criatividade.

Para Ramos (2005), a exposição a diferentes pontos de vista torna a aprendizagem mais rica que a exposição a uma visão única, a do professor, já que o conhecimento é socialmente construído através de um processo de negociação e interação com outros e com a sua compreensão dos fatos.

É nesse sentido que a perspectiva da educomunicação vem tentar diminuir a distância entre as gerações de educandos e educadores. Através das intervenções educomunicativas propostas pela disciplina nas escolas de educação formal vamos fazendo propostas, ampliando as discussões sobre 
o âmbito Educação-comunicação-tecnologias e aplicando projetos que possibilitam uma maior liberdade no processo de ensinar-aprender-pesquisar.

Diante das bibliografias pesquisadas e estudadas entendemos que a Educomunicação é um campo de conhecimento que propicia a integração e aproximação do professores e professoras com formação e experiências no século XX com a geração de nativos digitais do século XXI. É o caminho para motivar e despertar crianças, adolescentes e jovens para o ensino e aprendizagem tornando a docência mais instigadora a prazerosa.

\section{REFERÊNCIAS}

ALVES, Patrícia Horta. Educomunicação: a experiência do Núcleo de Comunicação e Educação. Mestrado, ECA-USP, 2002.

BELLONI, M.L. O que é mídia-educação. Campinas: Autores Associados, 2001.

BORDENAVE, Juan Diaz; CARVALHO, Horácio Martins de. Comunicação e planejamento. Rio de Janeiro: Paz e Terra, 1979.

BRUNI, Isabella. L'Educomunizazione brasiliana sulle onde della radio. Analisi di Caso. Roma: Università La Sapienza, 2010.

BUCKINGHAM, David. Watching Media Learning. Making Sense of Media Education. Londres: Falmer, 1990.

CANCLINI, Néstor. Consumidores e cidadãos. Rio de Janeiro: UFRY, 1995.

CITELLI, Adilson Odair; COSTA, Maria Cristina Castilho. Educomunicação - construindo uma nova área de conhecimento. São Paulo: Paulinas, 2011.

CITELLI, A. Outras linguagens na escola. São Paulo: Cortez, 2000.

DEVADOSS, Joseph Sagayaraj. Media Education, Key Concepts, Perspectives, Difficulties and Main Paradigms. Chennai, Índia: Arubu Publications, 2006.

FANTIN, Monica. Mídia-educação: conceitos, experiências e diálogos Brasil - Itália. Florianópolis: Cidade Futura, 2006. 
FREIRE, Paulo. Educação como prática da liberdade. Rio de Janeiro: Paz eTerra, 1967.

GOMES, Pedro Gilberto; SOARES, Ismar de Oliveira. Da formação do senso crítico à educação para a comunicação. São Paulo: Edições Loyola, 1988.

GUTIÉRREZ, Francisco. Educación y comunicación em el Proyecto Principal.Santiago do Chile: Unesco, 1984.

KAPLÚM, Mario. Processos educativos e canais de comunicação. Revista Comunicação \& Educação, São Paulo, Moderna/Eca-Usp, jan./abr. de 1999, p. 68-75.

KAPLÚN, Gabriel. Comunicación, educación y movimientos sociales: paradojas técnico-políticas. In: BOLAÑO et al (orgs.). Comunicación, educación y movimientos sociales en América Latina. Brasília: Casa das Musas, 2009.

LASWELL; SCHRAMM. Proceso y efectos de la Comunicación Colectiva.Quito: Ciespal, 1964.

MARQUES DE MELO, José; TOSTA, Sandra Pereira. (orgs.). Mídia \&Educação. Belo Horizonte, Autêntica, 2008.

MARTÍN-BARBERO, Jesús. Comunicação e Mediações Culturais. Revista Brasileira de Comunicação, São Paulo, vol. XXIII, n. 1, jan./jun. 2000.

MARTÍN-BARBERO, Jesús. Desafios culturais da comunicação à educação. Revista Comunicação \& Educação, n. 18, p. 51-61, maio/ago, 2000. Disponível em: www.conedu.com.br

MESSIAS, Claudio. Duas décadas de Educomunicação. Da crítica ao espetáculo. Dissertação de Mestrado, USP, 2011.

MIRANDA, Martín (ed.). Educación para la comunicación. Manual Latinoamericano. Santiago do Chile: Unicef/Ceneca, 1992.

PERUZZO, Cicilia M. K. Comunicação comunitária e educação para a cidadania. Revista PCLA Pensamento Comunicacional latino Americano. São Bernardo do Campo: Cátedra Unesco-Umesp, v. 4, n. 1, p. 1-9, 2002. 
PINHEIRO, Rose Mara. Educomunicação nos centros de pesquisa do país: um mapeamento das teses e dissertações disponíveis no banco da Capes. Tese de Doutorado, USP, 2013.

RAMOS, M. A. (2005). Crianças, Tecnologias e Aprendizagem: contributo para uma teoria substantiva. In B. D. Silva \& L. S. Almeida (Coord.), Atas do VIII Congresso Galaico-Português de Psicopedagogia (pp. 3709-3724). Braga: CIEd. Disponível em: htpp://hdl.handle. net/1822/33825 Acessado em: outubro de 2015.

RAMOS, Pablo. Tres décadas de Educomunicación en América Latina: los caminos del plan DENI. OCLACC - Organización Católica Latinoamericana y Caribeña de Comunicación, Quito, 2001.

SAYAD, Alexandre Le Voci. Idade mídia: a comunicação reinventada na escola. São Paulo: Aleph, 2012.

SETTON, Maria da Graça. Mídia e Educação. São Paulo: Editora Contexto, 2010.

SILVA FILHO, Genésio Zeferino. Educomunicação e sua metodologia: um estudo a partir de ONGs no Brasil. Tese de Doutorado, ECA-USP, 2004.

SOARES, Ana Carolina Altieri. Educomunicação e cidadania na América Latina, a interface comunicação/educação a partir das práticas sociais no continente: um estudo de caso das políticas públicas na Argentina e no Brasil. Dissertação de Mestrado, Prolam-USP, 2012.

SOARES, Ismar de Oliveira. Do Santo Ofício à Libertação. São Paulo: Paulinas, 1988.

SOARES, Ismar de Oliveira. Gestão comunicativa e educação: caminhos da educomunicação. Revista Comunicação \& Educação, n. 23, p. 16-25, 2002.

SOARES, Ismar de Oliveira. Educomunicação: o conceito, o profissional, a aplicação: contribuições para areforma do ensino médio. São Paulo: Paulinas, 2011. 
